User Program Division

Advanced Photon Source, Argonne National Laboratory

Argonne, IL 60439

A Water-Cooled X-ray Monochromator for Using Off-Axis Undulator Beam

A. Khounsary, J. Maser

Aug. 21-25, 2000

\begin{abstract}
The submitted manuscript has been created by
the University of Chicago as Operator of

Argonne National Laboratory ("Argonne") under

Contract No. W-31-109-ENG-38 with the U.S.

Department of Energy. The U.S. Government

retains for itself, and others acting on its bebalf

a paid-up, nonexclusive, irrevocable worldwide

license in said article to reproduce, prepare

derivative works, distribute copies to the public,

and perform publicly and display publicly, by

or on behalf of the Govermment.
\end{abstract}

To be submitted at SRI 2000 Conference Proceedings.

*This work is supported by the U.S. Department of Energy, Basic Energy Sciences-Materials Sciences, under contract \#W-31-109-ENG-38. 


\section{DISCLAIMER}

This report was prepared as an account of work sponsored by an agency of the United States Government. Neither the United States Government nor any agency thereof, nor any of their employees, make any warranty, express or implied, or assumes any legal liability or responsibility for the accuracy, completeness, or usefulness of any information, apparatus, product, or process disclosed, or represents that its use would not infringe privately owned rights. Reference herein to any specific commercial product, process, or service by trade name, trademark, manufacturer, or otherwise does not necessarily constitute or imply its endorsement, recommendation, or favoring by the United States Government or any agency thereof. The views and opinions of authors expressed herein do not necessarily state or reflect those of the United States Government or any agency thereof. 


\section{DISCLAIMER}

Portions of this document may be illegible in electronic image products. Images are produced from the best available original document. 


\title{
A Water-Cooled X-ray Monochromator for Using Off-Axis Undulator
}

\author{
Beam \\ Ali Khounsary* and Jörg Maser \\ (final Shortend Version, Nov. 29-00) \\ Advanced Photon Source \\ PECEVE \\ JAN $O 52001$ \\ OSTI \\ Argonne National Laboratory \\ Argonne, IL 60439, USA
}

Abstract

Undulator beamlines at third-generation synchrotron $\mathrm{x}$-ray sources are designed to use the high-brilliance radiation that is contained in the central cone of the generated $\mathrm{x}$-ray beams. The rest of the $\mathrm{x}$-ray beam is often unused. Moreover, in some cases, such as in the zone-plate-based microfocusing beamlines, only a small part of the central radiation cone around the optical axis is used.

In this paper, a side-station branch line at the Advanced Photon Source that takes advantage of some of the unused off-axis photons in a microfocusing x-ray beamline is described. Detailed information on the design and analysis of a high-heat-load water-cooled monochromator developed for this beamline is provided. 
PACS: 41.50.th, 07.85.Qe, 07.10.-h, 87.64.Bx

Keywords: x-ray, optics, monochromator, cooling, thermal management, beamline, undulator

\section{Introduction}

Undulator x-ray sources are notable for the high-brilliance harmonic radiation they produce. The harmonic radiation is spatially confined to the central cone of the beam. Whereas the entire beam has a divergence of about $1 / \gamma$ in the vertical direction and $2 \mathrm{~K} / \gamma$ in the horizontal, the harmonic radiation is confined to a central cone of about $(1 / \gamma) / \sqrt{\mathrm{nN}}$ (in the small particle beam emittance limit). Here, $\gamma$ is a parameter related to the orbiting electron energy, $\mathrm{n}$ is the harmonic order, $\mathrm{N}$ is the number of undulator periods, and $\mathrm{K}$ is the device deflection parameter, which is about 1 for undulators. For the Advanced Photon Source (APS) ring, $1 / \gamma$ is 73 $\mu \mathrm{rad}$. Therefore, for a device, such as the APS undulator A, which has 73 periods, the first harmonic radiation is confined to a central cone of about $(73 / \sqrt{ } 73 \approx) 9 \mu \mathrm{rad}$ angular divergence, versus $73 \mu \mathrm{m}$ plus for the entire beam. At a location about $30 \mathrm{~m}$ from the source where the beamline optical elements are placed, the entire undulator A beam full width half 
maximum is about $2 \mathrm{~mm}$ vertically and $4 \mathrm{~mm}$ horizontally. The first harmonic cone, however, is about $0.25 \mathrm{~mm}$ in diameter.

Most undulator beamlines make use of some or the entire central radiation cone with no provision to use the substantial number of photons present outside this region. In the following, an x-ray branch line designed to take advantage of some of the spatially unused photons in the main $\mathrm{x}$ ray microscopy beamline at the APS Sector 2 is described.

\section{Description of the Branch Line}

At sector 2 at the APS [1], there are two undulators in tandem producing a coincident, tunable, high-brilliance $\mathrm{x}$-ray beam. One is undulator $\mathrm{A}$, with a magnetic period of $33 \mathrm{~mm}$, and the other is an intermediate-energy undulator with a period $55 \mathrm{~mm}$. Either one or both (simultaneously) may generate radiation. The generated $\mathrm{x}$-ray beam is low-pass filtered by a water-cooled mirror [2], yielding a so-called "pink" beam, with energy cut offs selectable to $12 \mathrm{keV}, 22 \mathrm{keV}$, and $32 \mathrm{keV}$, depending on the material of the coated strip on the mirror from which the beam is reflected. The main part of the low-pass filtered pink beam (Fig. 1) proceeds directly to a water-cooled silicon crystal [3] in a Kohzu monochromator and into the hard x-ray microprobe setup, which includes a zone plate that intercepts 
about $100-250 \mu \mathrm{m}$ of the undulator central cone [1]. To deflect the outboard part of the beam into the side station, a horizontally diffracting $\mathrm{Si}$ crystal is inserted sideways into the pink beam as shown in Fig. 1. The resulting monochromatic beam is focused by a Fresnel zone plate to a small spot as part of a dedicated $\mathrm{x}$-ray fluorescence microprobe in the side station. Perfect silicon crystals in $<111>$ and $<220>$ orientations are used to provide photon energies in the $8-10 \mathrm{keV}$ and $12-13 \mathrm{keV}$ energy ranges, respectively. Diffraction is symmetric with the diffracting surface of the crystal making a $14^{\circ}$ angle with the incoming beam.

An alternative design could use thin single-crystal diamonds mounted on a cooled frame as demonstrated in the troika geometry beamline at the ESRF [4].

\section{Branch Line Operation Modes}

In order to take advantage of the spatial distribution of different spectral components of the undulator beam, the side branch can be operated in one of two different modes, depending on the requirements of the main beamline. The first mode is for operation in situations that the main beamline requires a spatially coherent "source" for high-resolution experiments. This necessitates the use of a horizontal slit upstream of the 
beam-splitting monochromator. The slit chops off the horizontal extent of the undulator beam significantly. In such a case, the upper or lower part of the undulator beam is utilized. For example, the lower step of the beamsplitting crystal, shown in Fig. 2, can be inserted into the lower part of the beam (i.e., below the optical axis) such that the central radiation cone passes on undisturbed. By detuning the crystal by $200-1000 \mathrm{eV}$ from the harmonic energy of the undulator, a significant number of photons present approximately $1 \mathrm{~mm}$ above and below the optical axis are harnessed.

If, on the other hand, no upstream slit is used, the beam-splitting crystal is positioned about $300 \mu \mathrm{m}$ from the center of the undulator beam to diffract horizontally an outboard portion of the beam into the side branch. In this mode of operation, a monochromatic beam flux density of about $10^{12}$ photons $/ \mathrm{s}-\mu \mathrm{m}^{2}$ can be obtained at or below the harmonic energy of the undulator.

Measurements made and presented in Fig. 3 provide one illustration of the distribution of photons outside the central cone. In this experiment, a 1 $\mathrm{mm}^{2}$ pinhole, positioned $500 \mu \mathrm{m}$ horizontally away from the undulator axis, is scanned vertically through the diffracted beam $0.5 \mathrm{~m}$ downstream of the beam splitting crystal. For ease of operation, instead of the usual scanning of the monochromator through different photon energies for a 
fixed undulator gap, the reverse is done. The monochromator is fixed to deflect $8.25 \mathrm{keV}$ photons, and the undulator $\mathrm{A}$ gap is changed such that the beam first harmonic is at $8,8.25,8.50$, or $10 \mathrm{keV}$. Figure 3 shows that (a) a considerable number of photons are present even at $0.5 \mathrm{~mm}$ from the beam axis, (b) gap detuning reduces the flux density only by a small amount (cf., the 8.25 and $8.5 \mathrm{keV}$ curves), (c) as the crystal/undulator gap detuning is increased, the maxima of the curves move to locations a mm or more above and below the optical axis, and (d) even with larger detuning of the undulator, a significant number of photons can still be delivered to the side branch. The availability of the two undulators provides additional flexibility in the operation of the side station in that both undulators can be run simultaneously with the $55-\mathrm{mm}$-period undulator tuned to the photon energy needed in the side station. At large $(>25 \mathrm{~mm})$ gaps, the combined heat load from the two undulator is rather small.

\section{Thermal Load on the Crystal Monochromator}

Most of the undulator beamline monochromators at the APS are cryogenically cooled. The combination of an upstream mirror and a long source-to-monochromator distance, however, makes it possible to handle the thermal load of the $\mathrm{x}$-ray beams with water-cooled monochromators 
[3]. At the monochromator $61 \mathrm{~m}$ from the source, the raw peak normal incident heat flux of either undulator beams (at a closed gap of $10.5 \mathrm{~mm}$ ) is about $45 \mathrm{~W} / \mathrm{mm}^{2}$. The upstream mirror substantially reduces this heat load. In fact, the normal incident heat flux at the monochromator does not exceed $15 \mathrm{~W} / \mathrm{mm}^{2}$ (Table 1). The peak normal incidence heat flux at this crystal is often less than $15 \mathrm{~W} / \mathrm{mm}^{2}$. In addition, unlike the raw undulator beam, the beam reflected from the mirror has a substantially uniform spatial distribution at all undulator gaps.

\section{Analysis}

In order to determine the expected thermal distortion in the beamsplitting crystal, the monochromator with the geometric the configuration shown in Fig. 2 was conceived and analyzed. The overall dimensions are less than $10 \mathrm{~mm} \times 10 \mathrm{~mm} \times 15 \mathrm{~mm}$. The incident beam strikes the monochromator at about $14^{\circ}$ with respect to the surface. An upstream aperture adjusts the dimension of the incident beam on the crystal. The crystal is cooled on its bottom, left, and possibly top sides. Cooling is accomplished by placing the monochromator into a water-cooled copper cradle with an In/Ga eutectic providing the interstitial medium. This cooling scheme is similar to that used elsewhere on the main beamline [3]. 
An effective heat transfer coefficient of $7 \mathrm{~kW} / \mathrm{m}^{2}-\mathrm{K}$ at the copper-silicon interface is assumed.

For the present study, a uniform incident heat flux of $8.5 \mathrm{~W} / \mathrm{mm}^{2}$ is assumed. This is the maximum heat flux expected when using the rhodium-coated strip of the mirror, which reflects photons with energies up to $22 \mathrm{keV}$, well beyond the anticipated $13.5 \mathrm{keV}$ energy limit dictated by physical constraints in the side station.

Table 2 shows the expected temperature rise as well as the maximum tangential and sagittal slope errors over the entire incident beam footprint and over a $250 \mu \mathrm{m} \times 250 \mu \mathrm{m}$ central part of the footprint. The latter values are particularly meaningful since the zone plate downstream of this monochromator typically uses a $250-\mu \mathrm{m}$-diameter monochromatized beam. Data show that assuming a $2 \mathrm{~mm}(\mathrm{~h}) \times 0.5 \mathrm{~mm}(\mathrm{v})$ beam and allowing half of it to be intercepted by the beam-splitting crystal (and the other half to proceed into the main $\mathrm{x}$-ray microscopy beamline) will satisfy the needs at both stations, and that the maximum slope error in the central $0.25 \mathrm{~mm} \times 0.25 \mathrm{~mm}$ area of the side-station monochromator is less than 2 arcseconds (Table 2, last case).

\section{Summary and Conclusions}


An undulator side station to take advantage of a small part of the substantially unused portions of an undulator beam was described, and the design and analysis of a key water-cooled monochromator for this branch line were provided. A combination of three factors (a) an upstream powerfiltering mirror, (b) a large distance from the source, and (c) a modest beam size makes the design and use of this water-cooled monochromator possible. Thermally induced slope errors are rather small and are less than 2 arcseconds for all intended operational modes.

The x-ray fluorescence microprobe operated at the side station effectively doubles the beamline capacity at a comparatively modest cost. The beam brilliance in the branch line approaches that of the main beamline.

\section{Acknowledgement}

Use of the Advanced Photon Source was supported by the U.S. Department of Energy, Basic Energy Sciences, Office of Energy Research, under Contract No. W-31-109-Eng-38.

\section{References}


[1] W. Yun, B. Lai, D. Shu, A. Khounsary, Z. Cai, J. Barraza, D. Legnini, Rev. Sci. Instrum. 67 (9), CD-ROM, 1996.

[2] Khounsary, A.M. and W. Yun, Rev. Sci. Inst., 67 (9), CD-ROM, 1996.

[3] Khounsary, A. M., W. Yun, E. Trakhtenberg, S. Xu, L. Assoufid, and W-K. Lee, Proc. SPIE Vol. 2855, p. 232-239, 1996.

[4] G. Grübel and J. Als-Nielsen, ESRF Annual Report1994/1995, ESRF, BP220, 38043 Grenoble, France, 1995. 


\section{Figure Captions}

Figure 1: A top schematic view of the side-station branch line at APS sector 2 .

Figure 2: Beam-splitting crystal geometry showing a typical beam footprint (see text).

Figure 3: Measured spatial distribution of photons (see text). 
Table 1: Peak Normal Incidence Heat Flux at the Beam Splitting Crystal.

\begin{tabular}{|c|c|c|c|c|c|c|c|}
\hline \multirow[t]{2}{*}{$\begin{array}{l}\text { Gap } \\
(\mathrm{mm})\end{array}$} & \multirow[t]{2}{*}{$\begin{array}{c}\mathrm{E}_{1} \\
(\mathrm{keV})\end{array}$} & \multirow[t]{2}{*}{$\begin{array}{c}\mathrm{E}_{3} \\
(\mathrm{keV})\end{array}$} & \multirow[t]{2}{*}{$\begin{array}{l}\mathrm{K} \\
(-)\end{array}$} & \multicolumn{4}{|c|}{$\begin{array}{l}\text { Peak Normal Incidence Heat Flux With } \\
\text { Various Mirror Coatings }\left(\mathrm{W} / \mathrm{mm}^{2}\right)^{*}\end{array}$} \\
\hline & & & & $\mathrm{Si}$ & $\mathrm{Rh}$ & $\mathrm{Pt}$ & Entire Spectrum \\
\hline 10.5 & 2.9 & 9 & 2.78 & 3.2 & 8.5 & 14.1 & 45 \\
\hline 11.5 & 3.5 & 11 & 2.46 & 3.0 & 8.5 & 14.2 & 37 \\
\hline 13.5 & 4.7 & 14 & 2.00 & 4.7 & 9.6 & 14.5 & 32 \\
\hline 15.5 & 6.1 & 18 & 1.63 & 4.0 & 9.9 & 14.0 & 26 \\
\hline 18.5 & 8.1 & 27 & 1.21 & 5.5 & 9.3 & 12.1 & 18 \\
\hline 25 & 12 & 36 & 0.6 & 0 & 4.8 & 5.3 & 8 \\
\hline
\end{tabular}

*Energy cut offs of 10,20 , and $30 \mathrm{keV}$ for $\mathrm{Si}, \mathrm{Rh}$, and Pt @ $0.15^{\circ}$ are used. 
Table 2: Temperature and Tangential Slope in the Beam-Splitting Crystal (a normal incidence uniform heat flux of $8.5 \mathrm{~W} / \mathrm{mm}^{2}$ is assumed).

\begin{tabular}{|c|c|c|c|c|c|}
\hline $\begin{array}{l}\text { Beam } \\
\text { Size* }\end{array}$ & $\begin{array}{c}\text { Max. } \\
\text { Temperature }\end{array}$ & \multicolumn{4}{|c|}{$\begin{array}{c}\text { Max. Slope } \\
(\mu \mathrm{rad})\end{array}$} \\
\hline $\mathrm{hxv}$ & Rise & \multicolumn{2}{|c|}{$\begin{array}{c}\text { Over Entire Beam } \\
\text { Footprint }\end{array}$} & \multicolumn{2}{|c|}{$\begin{array}{c}\text { Over } 250 \mu \mathrm{m} \times 250 \mu \mathrm{m} \\
\text { footprint }\end{array}$} \\
\hline$(\mathrm{mm})$ & $\left({ }^{\circ} \mathrm{C}\right)$ & Sagittal & Tangential & Sagittal & Tangential \\
\hline $1.0 \times 0.5$ & 9 & 15 & 17 & 8 & 8 \\
\hline $1.0 \times 1.0$ & 14 & 29 & 30 & 7 & 15 \\
\hline $1.0 \times 5.0$ & 33 & 125 & 65 & 6 & 32 \\
\hline $2.0 \times 0.5$ & 11 & 18 & 23 & 9 & 6 \\
\hline
\end{tabular}

* Only a horizontal half of the indicated beam is intercepted by the crystal. 


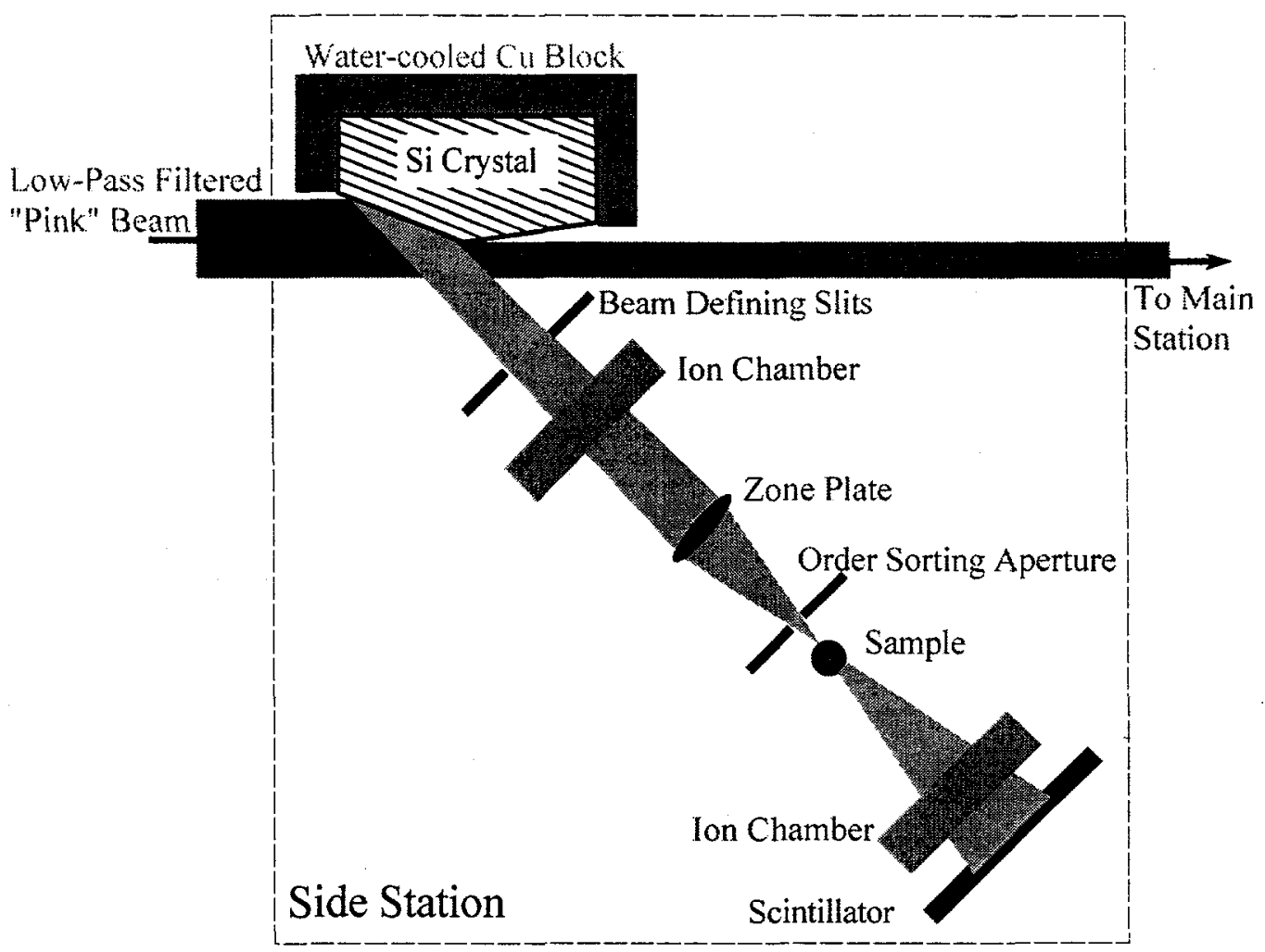

Figure 1 


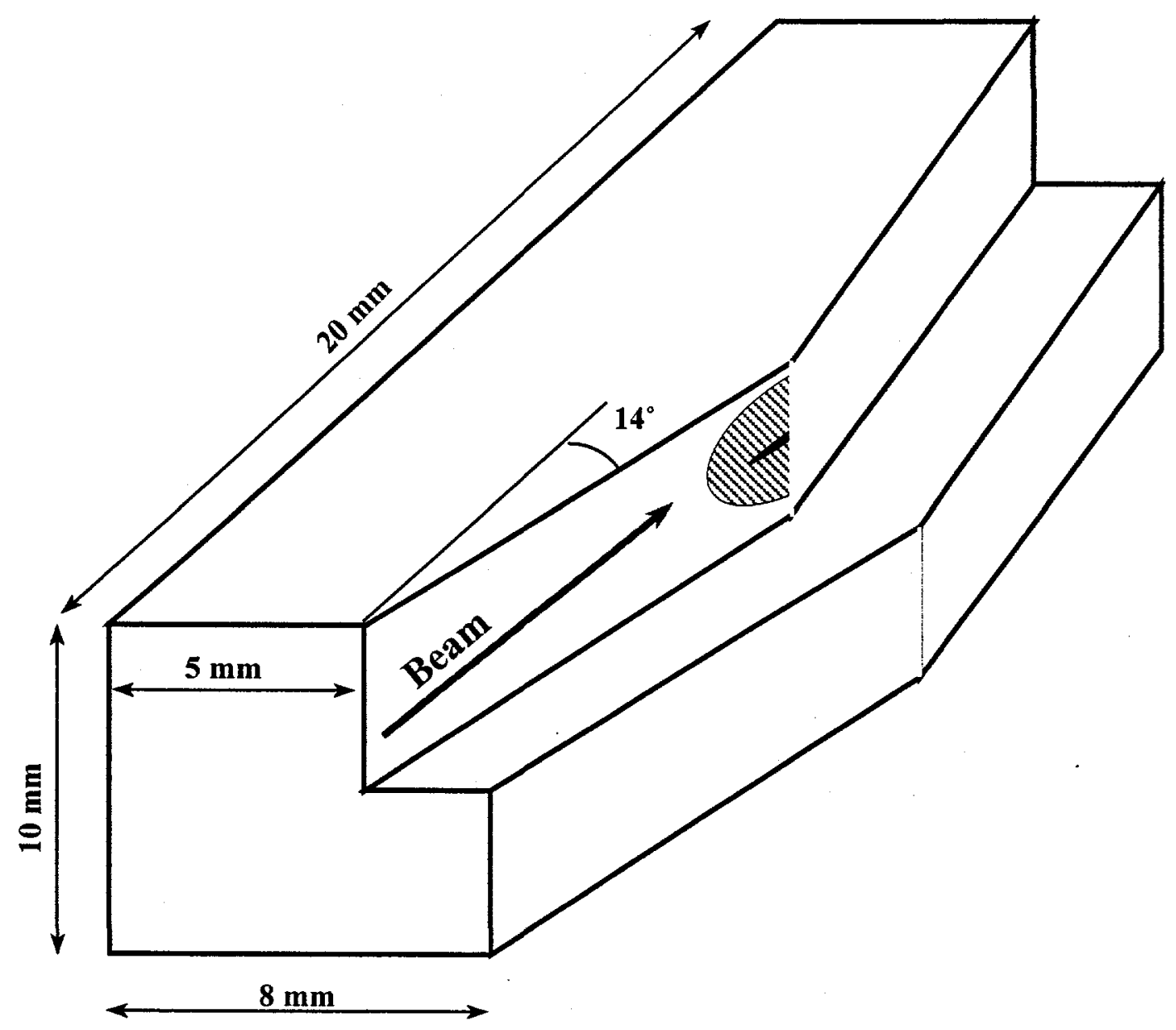

Figure 2 


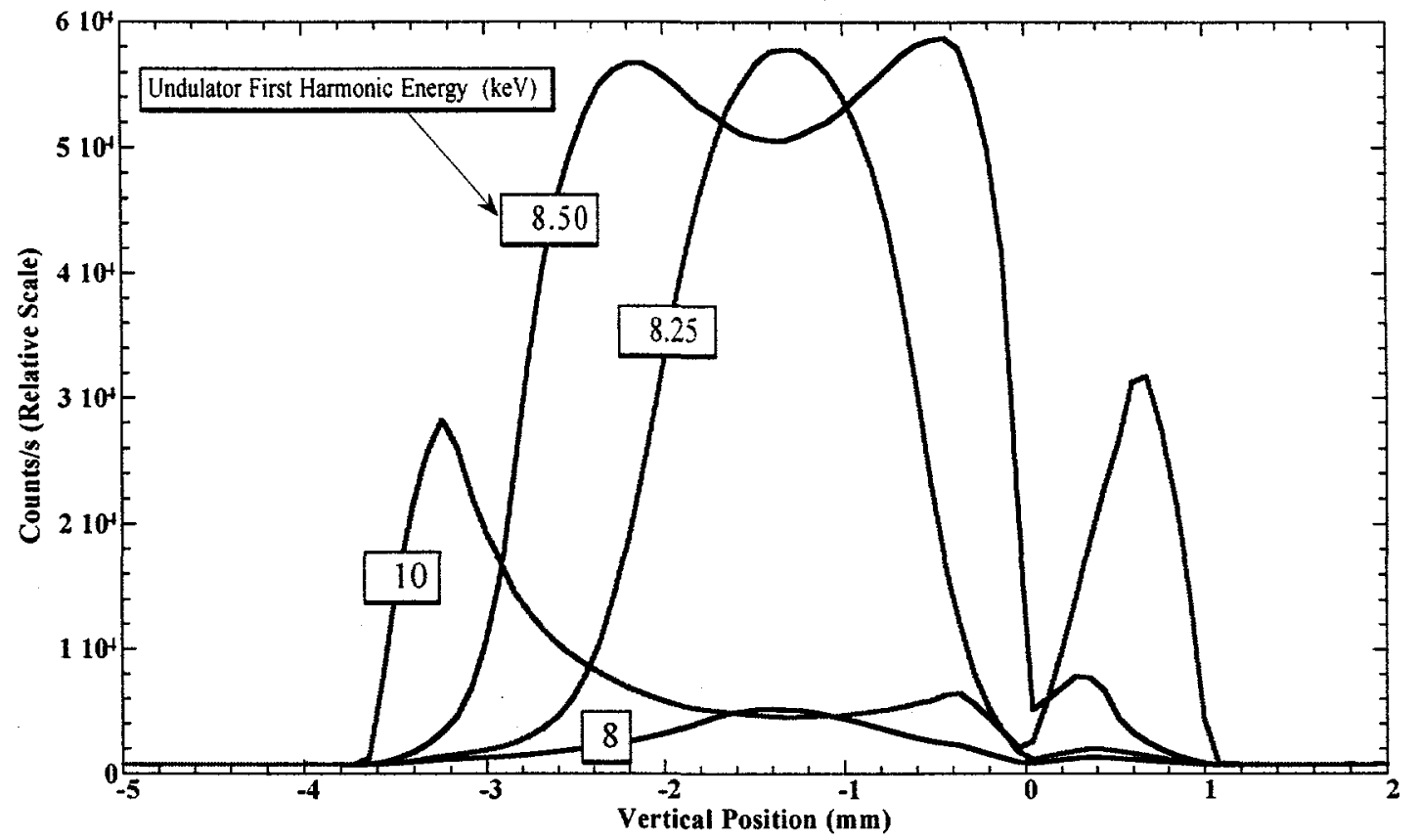

Figure 3 